\title{
ESTUDIOS
}

\section{LA VERTIENTE HISTOLÓGICA DE JOSÉ FERNÁNDEZ NONÍDEZ. INTRODUCTOR DE LA TEORÍA MENDELIANO-CROMOSÓMICA EN ESPAÑA*}

\author{
Susana Pinar \\ Depto. Historia de la Ciencia, IH, CSIC
}

\section{RESUMEN}

En el presente artículo se quiere dar a conocer la labor de José Fernández Nonídez, quien fuera introductor de la teoría mendeliano-cromosómica en España, como histólogo en los Estados Unidos. Sus estudios sobre las células parafoliculares del tiroides, su descripción del glomus aorticum y, en especial, la aplicación de las técnicas de impregnación argéntica de la Escuela Histológica Española le acercan a la tradición y a las líneas de investigación de este grupo, a pesar de su distancia geográfica.

PALABRAS CLAVE: histología, teoría mendelismo-cromosómica, Fernández Nonídez, siglo XX.

\section{SUMMARY}

On this paper I would like to show the histological research of José Fernández Nonídez, who was the introducer of the Mendelian-Chromosome Theory in Spain. His studies on the parafollicular cells of thyroid, his description of the glomus aorticum and, in particular, the application of silver staining techniques from the Spanish School of Histology, bring him close to the tradition and research lines of this group, despite his career was done at the Unites States.

KEY WORDS: histology, mendelism.chromosome theory, Fernández Nonidez, $20^{\text {th }}$ century.

* Este artículo ha sido realizado gracias a una beca del programa Fulbright/MEC, FU97 2883722. 


\section{INTRODUCCIÓN}

Este artículo viene a completar aquel otro, publicado en esta misma revista ${ }^{1}$, sobre la figura de José Fernández Nonídez como introductor en España de la teoría mendeliano-cromosómica elaborada por el genético americano Thomas H. Morgan (18661945), quien recibió por la misma el premio Nobel de Fisiología y Medicina en 1933. Nonídez cumplió su función de introductor de la nueva genética gracias a la política de pensionados en el extranjero que la Junta para la Ampliación de Estudios mantuvo con objeto de mejorar el nivel científico español desde su creación, en 1907, y hasta su disolución tras la guerra civil. Sin embargo, en el presente artículo se tratará únicamente de las investigaciones histológicas que Nonídez llevó a cabo tras su regreso a los Estados Unidos, dando a conocer una faceta de su carrera que es desconocida en nuestro país, si bien no así en el extranjero, y que no pudo ser completada en su momento. Del mismo modo, ello nos permitirá hacer un repaso a alguna de las cuestiones relevantes de la biología de la primera mitad del siglo XX.

Resumiendo rápidamente los datos más esenciales que ofrecíamos en el artículo anterior. José Fernández Nonídez nació en Madrid el 22 de febrero de 1892 y murió a en los Estados Unidos el 27 de septiembre de 1947, cuando acababa de trasladarse para tomar posesión de un puesto como profesor de anatomía microscópica en la Universidad de Georgia en Augusta. Era licenciado en ciencias naturales por la Universidad Central de Madrid, donde obtuvo el título de doctor el 16 de febrero de 1916. Como complemento a su carrera, atendió a diversos cursos de ampliación de estudios en centros como el Museo de Ciencias Naturales de Madrid, donde siguió entre otros el curso sobre teorías y técnicas modernas en citología y embriología que impartía Antonio de Zulueta (1885-1971). Junto a él, Nonídez inició su carrera investigadora efectuando un estudio de citología aplicada a la herencia ${ }^{2}$, disciplina en pleno desarrollo que jugó un papel esencial al demostrar el paralelismo entre la segregación de los factores mendelianos y la formación de los gametos. Consecuentemente, las investigaciones sobre el comportamiento cromosómico durante la meiosis cobraron vital importancia durante esos años al dar fundamento citológico a la teoría cromosómica de la herencia desarrollada por Morgan en la década de 1910, quien aunó las teorías previas al situar a los factores mendelianos en los cromosomas, donde además habían de hallarse ordenados linealmente.

1 PINAR, S. (1999), La recepción de la teoría cromosómico-mendeliana en España. La contribución de José Fernández Nonídez. Asclepio, 51(1): 27-54.

2 NoníDEZ, J. F. (1914), «Los cromosomas en la espermatogénesis de Blaps lusitanica Herbst», Trab. Mus. Nac. Cienc. Nat., Ser. Zool.,18, 1-97; y NoníDEZ, J. F. (1915), «Estudios sobre las células sexuales. I. Los cromosomas goniales y las mitosis de maduración en Blaps lusitanica y B. waltli», Mem. R. Soc. Esp. Hist. Nat., 10, 149-190. 
Siendo ya catedrático de zoología en la Universidad de Murcia, Nonídez viajó como pensionado por la JAE al departamento de zoología de la Columbia University que dirigía el celebre citólogo Edmund B. Wilson ${ }^{3}$ (1856-1936), en 1917. Junto a Wilson y Morgan, Nonídez se familiarizó con los métodos de investigación empleados en el estudio de la herencia, realizando diversos estudios de carácter principalmente citológico ${ }^{4}$. Cuando en 1920 volvió a España, Zulueta y el director del Museo de Ciencias Naturales, Ignacio Bolívar, le propusieron que impartiera en un cursillo la teoría de la herencia de Morgan, cumpliendo así con los deseos de difusión de la JAE. El cursillo se celebró ese mismo verano y su contenido fue publicado por la JAE con el título La herencia mendeliana: Introducción al estudio de la genética (1922), primer texto en castellano que recogió detalladamente no sólo la teoría mendeliana clásica, sino también todos los descubrimientos efectuados en el grupo de Morgan hasta ese momento (teoría cromosómico-mendeliana, ligamiento, intercambio cromosómico, cartografía de cromosomas, el fenómeno de no-disyunción, las interferencias, etc.), incluyendo dos apéndices con instrucciones prácticas para iniciar estudios genéticos en plantas y animales, con especial mención a la experimentación en Drosophila. Herencia mendeliana fue seguido por otro volumen dando cuenta de la Variación y herencia en los animales domésticos y las plantas cultivadas (1923). Esta segunda obra de Nonídez tuvo también gran repercusión entre los ingenieros agrónomos y los veterinarios españoles y sudamericanos de la época, llegando a ser editada cuatro veces entre 1923 y $1946^{9}$. En lo que respecta a Herencia mendeliana, ésta fue reeditada en 1935 con grandes modificaciones para incluir los nuevos descubrimientos efectuados en los 12 años que mediaron hasta su reedición tanto por el equipo de Morgan como por otros investigadores (los cromosomas sexuales en las plantas dioicas, intersexualidad en Lymantria y Drosophila, fenómenos de hipostasia y epistasia, traslocaciones, delecciones, duplicaciones e inversiones de segmentos cromosómicos, etc.).

3 EDMUND B. Wilson ha sido considerado el artífice de la transición naturalista-experimentalista efectuada en la biología americana durante el cambio de siglo. Su carrera científica puede dividirse en tres etapas principales. De 1879 a 1891, Wilson trabajó en embriología y morfología descriptiva. Entre 1891 y 1903 se dedicó al estudio experimental de la embriología, la diferenciación y la partenogénesis artificial. Por último, de 1903 a 1938, sus investigaciones se concentraron en buscar una base celular a la herencia, reconociendo tempranamente la importancia de los cromosomas en la misma. Entre otros muchos estudios del americano, destacan el descubrimiento ocasional de la no disyunción de los cromosomas X e Y durante la meiosis, los estudios sobre cromosomas sexuales en insectos, haber encontrado evidencias durante la sinapsis de entrecruzamiento o crossing-over entre cromosomas homólogos y sus investigaciones sobre la herencia extracromosomal. AlLEN, G. E.; WILSON, B.E.; GiLlisPIE Ch. C. (eds.) (1976), Edmund Dictionary of Scientific Biography, Charles Scribner's Sons, vol. XIV, pp. 423-436.

4 NoníDEZ, J. F. (1920a), «The Meiotic Phenomena in the Spermatogenesis of Blaps with Special Reference to the X-Complex», J. Morphology, 1, 69-103. Nonídez, J. F. (1920b), «The Internal Phenomena of Reproduction in Drosophila», Biolog. Bulletin, 39, 207-230, y METz, Ch. W. \& NoníDEZ, J. F. (1921), «Spermatogenesis of the Fly Asilus sericeus Say», J. Exper. Zoology, 32, 165-186. 
Sin embargo, la labor de Nonídez en favor de la introducción de la genética morganiana en España terminó aquí. El relevo fue recogido por Antonio de Zulueta quien, desde su puesto en el Laboratorio de Biología del Museo de Ciencias Naturales, dio a conocer la incipiente genética española a nivel internacional y llevó a cabo una importante labor para el desarrollo institucional de esta disciplina en España ${ }^{5}$. De este modo, a los pocos meses de regresar a España, Nonídez volvió a marcharse a los Estados Unidos, rechazando un puesto de histólogo en la recién creada Misión Biológica de Galicia e incorporándose definitivamente al departamento de anatomía de la Universidad de Cornell, donde permaneció hasta poco antes de su muerte.

$\mathrm{Su}$ caso no es único. Fueron bastantes los científicos españoles que, dada la situación económica de España en el primer tercio del siglo XX y a pesar de los esfuerzos de la JAE por formarlos, decidieron aceptar posiciones en los Estados Unidos o allí donde las condiciones para desarrollar la actividad científica eran mas favorables. Estos abandonos fueron una gran preocupación para Santiago Ramón y Cajal (18521934), presidente de la JAE, quien con motivo de la marcha a los Estados Unidos de su discípulo Rafael Lorente de Nó (1902-1991), comentaba a José Castillejo (18771946), secretario de la misma: «A mi juicio, salvo alguna excepción, no deberíamos pensionar más que a auxiliares y a catedráticos. Abriendo la mano, no hacemos sino exportar a los Estados Unidos lo poco bueno que tenemos» ${ }^{6}$.

Estados Unidos se convirtió en el hogar de Nonídez. Allí desarrolló su carrera como histólogo y contrajo matrimonio dos veces, la primera con Winifred Kittredge Nonidez, activista del Southern Women's National Democratic Organization de New York y, posteriormente, en 1942, con Margaret Eggleston Brown, con quien tuvo dos hijos que quedaron huérfanos con muy pocos años cuando Nonídez murió en 1947.

5 CARBonell, F. (1974), La introducción de la genética mendeliana en España (1901-1935), Valencia, tesis (inédita); García Martínez, J. (1984), «Aportaciones a la historia de la genética española, (1920-1936), Madrid, Memoria de Licenciatura, Universidad Complutense de Madrid (inédita); VALDERAS, J. M ${ }^{\mathrm{a}}$. (1989), «La genética en la JAE. Antonio de Zulueta y Escolano (1885-1971)», en SÁNCHEZ Ron, J. M. (1989), 1907-1987. La Junta para Ampliación de Estudios e Investigaciones Científicas 80 años después, Madrid, Estudios sobre la Ciencia, CSIC, vol. II, pp. 401-428; BARATAS DÍAZ, L. A.; FERNÁNDEZ PÉREZ, J. (1989), «Los laboratorios de investigación genética de la Junta para la Ampliación de estudios», Dynamis, 9, 225-235 y PINAR, S. (1999), «La introducción de la genética en España durante el primer tercio del siglo XX», Llull, 22, 453-473.

6 Biblioteca Nacional, Carta-borrador (ca. IX-1930), Mss. 22112, n. 37. Citado en Rodríguez Quiroga, A. (1999), «De la neurohistología a la neurofisiología: la obra de Rafael Lorente de Nó», Arbor, CLXIII, 642, 187-203. 


\section{LA TRAYECTORIA CIENTÍFICA DE JOSÉ FERNÁNDEZ NONÍDEZ EN LOS ESTADOS UNIDOS}

\section{Histología de aves de corral}

Como se dijo anteriormente, la experiencia de Nonídez como pensionado en los Estados Unidos fue tan satisfactoria que a los pocos meses de volver a España decidió regresar a Nueva York, incorporándose definitivamente al departamento de anatomía de la Universidad de Cornell. A pesar de la distancia, en esta nueva etapa Nonídez siguió colaborando con España, no solo en los proyectos de publicación de sus obras sobre genética, ambas escritas en los Estados Unidos, sino también con la publicación en revistas españolas de parte de las investigaciones que ahora iba a emprender.

Los primeros estudios de Nonídez en Cornell fueron continuación de las investigaciones y colaboraciones, principalmente con genéticos americanos, efectuadas durante su estancia como pensionado de la JAE. Entre éstas cabe mencionar una serie de seis artículos publicados indistintamente en revistas especializadas españolas y norteamericanas, relativos al estudio de diferentes aspectos histológicos de las gónadas de gallinas de diferentes razas, a fin de averiguar la posible influencia que estos órganos tenían en la expresión de caracteres sexuales secundarios, como son el color y desarrollo de las plumas, crestas y espolones de los gallos ${ }^{7}$. Dichos estudios se remontan al invierno de 1920, durante los últimos meses en la Universidad de Columbia bajo la dirección de Morgan. Durante esos años, el grupo de Morgan estuvo dividido entre una elite cercana al proyecto de cartografiado, cuya carrera estaba volcada en el estudio de Drosophila, y el resto, cuyas expectativas u orientación eran las de zoólogos experimentales, grupo en donde había de incluirse por lo general a los investigadores visitantes, a los que se les solía ofrecer y dirigir hacia temas colaterales de investigación importantes para Morgan, quien siempre tenía entre manos proyectos muy diversos ${ }^{8}$. Durante esos años el éxito de su teoría llevó a Morgan a

7 NoníDEZ, J. F. (1920c), «Studies on the Gonads of the Fowl. I. Hematopoietic Processes in the Gonads of Embryos and Mature Birds», Am. J. Anatomy, 28(1), 81-107; NONíDEZ, J. F. (1922b), «Estudios sobre las gónadas de la gallina. II. El tejido intersticial del ovario». Libro en honor de D. Santiago Ramón y Cajal. Trabajos originales de sus admiradores y discipulos extranjeros y nacionales, Madrid, JAE, vol. 2, pp. 137-157; NoníDEZ, J. F. (1922c), «Studies on the Gonads of the Fowl. III. The Origin of the socalled Luteal Cells in the Testis of Hen-feathered Cocks», Am. J. Anatomy, 31(2), 109-124; Nonídez, J. F. (1924a), «Studies on the Gonads of the Fowl. IV. The Intertubular Tissues of the Testis in Normal and Hen-feathered Cocks», Am. J. Anatomy, 34 (2), 359-392; NONÍDEZ, J. F. (1924b), «Studies on the Gonads of the Fowl. V. The Effect of Ligation of the Vas Deferens on the Structure of the Testis», Am. J. Anato$m y, 34(2), 393-425$ y NONíDEZ, J. F. (1929), «Estudios sobre las gónadas de la gallina. -VI. La homología de los tubos seminíferos y los cordones medulares del ovario», Mem. R. Soc. Esp. Hist. Nat., 15: 131-142.

8 KOHLER, R. E. (1994), The Lords of the Fly. Drosophila Genetics and the Experimental Life, Chicago \& Londres, The University of Chicago Press, p. 96. 
reinterpretar frecuentemente la teoría de Darwin en términos de su nueva genética, así como aquéllos problemas relativos al desarrollo embriológico9.

En relación a la aparición de caracteres sexuales secundarios en distintas especies animales, Charles Darwin (1809-1882) y Alfred Russel Wallace (1823-1913) ya habían intentado dar explicación a este fenómeno en sus escritos. La teoría de la selección natural, que sobre este punto también mantuvo Wallace, se suponía operaba a través de la supervivencia de las hembras que poseían un plumaje protector, es decir, cuyos colores apagados permitían un mayor grado de camuflaje en comparación con los del macho. Por otra parte, la teoría de la selección sexual de Darwin asumía que el macho había adquirido los colores brillantes de su plumaje, la cresta y los espolones típicos de los gallos, como respuesta a la elección de los machos más vistosos y llamativos por las hembras.

Tanto para Morgan como para Hubert Dana Goodale ${ }^{10}$ (1879-1968), uno de los pioneros de la genética de aves de corral americana, amigo y colaborador de Morgan durante su época en el laboratorio del Cold Spring Harbor, ninguna de las dos teorías explicaban por completo el complejo problema de este tipo de caracteres secundarios. Para Goodale ambas teorías partían de un supuesto erróneo, es decir, de que la especie primigenia debía ser de colores apagados y ambos sexos poseer igual morfología, puesto que los experimentos de castración y extirpación de ovarios realizados por el mismo indicaban que en el plumaje de colores brillantes de la hembra era suprimido por la influencia de algún tipo de secreción del ovario, por lo tanto se había de partir del supuesto contrario, es decir, de la posesión de un plumaje de colores brillantes por la hembra ${ }^{11}$.

9 Morgan inició su carrera científica como embriólogo, rechazando tanto el mendelismo como la teoría cromosómica, si bien la primera presentaba algunas ventajas puesto que ayudaba, por su carácter matemático, a la sistematización de datos. Su trabajo experimental sobre Drosophila no comenzó hasta 1910-1911, si bien llegó a revolucionar la recién nacida genética con su teoría cromosómica de la herencia mendeliana. Entre otros: Allen, G. E. (1978), Thomas Hunt Morgan. The Mand and his Science,Princeton, University Press.

10 Goodale fue uno de los pioneros y líderes de la genética ganadera y de aves de corral. Graduado por el Trinity College de Connecticut en 1903, fue miembro de la Universidad de Columbia entre 1905 y 1906, doctorándose en zoología en 1913. Durante los años 1911 y 1913 trabajó en el laboratorio de genética del Cold Spring Harbor de Nueva York, dependiente del Carnegie Institute en Washington. Entre 1913 y 1922 trabajó en la cría de aves de corral en el Massachusetts Agricultural College y el resto de su vida activa (1922-1962) la pasó como genético en el Mount Hope Farm en Williamstown, Massachusetts. Sus investigaciones más importantes se centraron en demostrar el control del ovario en la expresión de los caracteres sexuales secundarios en aves, los factores que influyen en la producción de huevos y en su incremento, la genética de la producción de leche, selección natural en ratones, etc. CATTELL, J. (1960), American Men of Science. A Biographical Directory. The Physical and Biological Sciences, Tempe, Arizona, The Jacques Cattell Press, inc., p. 1452.

11 Goodale, H. D. (1916), Gonadectomy in Relation to the Secondary Sexual Characters of some Domestic Birds, Washington, Carnegie Institution, p. 49. 
A la luz de la nueva genética, Morgan manifestó también sus dudas sobre la teoría de la selección sexual de Darwin en 1919. Así, concluía que dicha teoría no podía ser de aplicación general, puesto que no podía dar respuesta a la aparición de los distintos tipos de caracteres sexuales presentes en todos los grupos animales, además del rechazo que provocaban las fuertes connotaciones antropomórficas de la teoría de Darwin. Por otra parte, Morgan pensaba que el nuevo conocimiento sobre la actuación de los genes permitía superar algunas limitaciones que no pudieron solventarse en época de Darwin. Así, para el caso del desarrollo «excesivo» de ciertos caracteres (color, espolones y cresta) en el macho, cuyos genes estaban presentes en ambos sexos, Morgan indicaba que podían ser fácilmente explicados puesto que «a single factorial difference may be at the root of exceedingly great differences in the individual. Such results, while they admittedly do not in most cases tell us that the differences involved have arisen at a single progressive step, show us nevertheless that such differences may depend on very simple initial differences, and if so, the entire problem becomes enormously simplified. To Darwin the excessive development of color and ornamentation appeared due to a long, slow process of evolution laboriously brought about by the female through selection of those males a little more ornamented than their fellows»; sin embargo, la única diferencia entre sexos se encontraba en la composición de sus cromosomas sexuales, de modo que en las hembras esto determinaba la producción de una sustancia que suprimía la expresión de dichos caracteres, señalando además que los caracteres sexuales secundarios podían simplemente ser un subproducto de genes que controlaban alguna otra importante función metabólica, como, por ejemplo, la regulación de la actividad, de la fuerza o de la energía. De este modo, el efecto secundario producto de la expresión de estos genes, en este caso la vistosa ornamentación de los gallos, no necesitaba de otro tipo de explicación distinta de lo que se entendía por selección natural ${ }^{12}$.

El paso siguiente hacia la solución de este problema fue la búsqueda de la posible sustancia que ejercía su efecto sobre la expresión de los caracteres sexuales secundarios. En 1918 Alice M. Boring y Morgan, estudiando los testículos de machos de la

12 El grupo de Morgan realizó diversos experimentos con Drosophila para testar la teoría de la selección natural de Darwin. En este caso, se midió la frecuencia de copulación de machos salvajes con hembras salvajes y con mutantes de ojos amarillos, luego con machos de ojos amarillos y el mismo tipo de hembras y, posteriormente, se repitió el experimento pero confrontando machos normales con otros de ojos blancos en el mismo tipo de cruces. Con ello se pretendía observar la existencia de algún tipo de elección por parte de los miembros de la pareja por separado. La conclusión fue que las diferencias en las frecuencias de apareamiento se debían a diferencias en la actividad de los componentes de la pareja. La mayor actividad mostrada por los machos normales suponía, al final, un mayor número de hembras cubiertas. La pasividad de las hembras de ojos blancos, determinaba su participación en un mayor número de apareamientos. Estos datos apuntaban a la existencia de otros factores de mayor influencia que la supuesta elección de un macho preciso por la hembra. MoRGAN, Th. H. (1919), The Genetic and the Operative Evidence Relating to Secondary Sexual Characters, Washington, Carnegie Institute, pp. 51-52. 
raza de gallinas Sebright, cuyo plumaje es siempre de carácter femenino, habían observado unas células intersticiales similares a la que aparecían en el ovario de las hembras ${ }^{13}$.Tanto la extirpación del ovario en hembras como la castración de este tipo de gallos en los que se presentaban las células intersticiales producían la aparición del plumaje característico de los machos, razón por lo que Morgan supuso que tales células debían tener una función endocrina. Mientras tanto, Raymond Pearl ${ }^{14}$ (18791940) y Boring ${ }^{15}$ llegaron a asimilar esas células, debido a la formación de un pigmento amarillo en su interior, con aquéllas otras células intersticiales del cuerpo lúteo de mamíferos, de probada influencia en la expresión de los caracteres sexuales secundarios. Los estudios que realizó Nonídez sobre el origen y función de las gónadas de aves de corral, probaron la errónea asimilación de esa formación con el cuerpo lúteo, al señalar que las masas de células intersticiales eran restos de los cordones sexuales y la sustancia amarilla producto de su degeneración.

En buena parte de los estudios de esta serie el material de trabajo fue cedido por el propio Morgan y por Goodale, quien había estudiado este punto junto al primero en años anteriores, si bien, posteriormente, se alió con Nonídez contribuyendo a que éste demostrara igualmente el error de la hipótesis secretora que Morgan elaboró para esas células ${ }^{16}$. Actualmente, la organogénesis gonadal de aves, aunque está por ser completada y muchos datos son inferidos de otras especies, muestra la existencia de receptores para la hormona luteinizante, segregada por la pituitaria, sobre las células intersticiales del ovario ${ }^{17}$.

13 Boring, A. M. \& Morgan, Th. H. (1918), «Luteal Cells and Hen-feathering», J. Gen. Physiol., 1, pp. 127-131. Un año más tarde, Morgan presentó todos los datos acumulados desde que empezara a trabajar sobre las bases genéticas y fisiológicas de los caracteres sexuales secundarios en aves, en el volumen: Morgan, Th. H. (1919), The Genetic and the Opperative Evidence Relating to Secondary Sexual Character, Washington D.C., Carnegie Institute of Washington Publication, n. 285.

14 Raymond Pearl fue profesor de la Universidad de Pennsylvania entre 1906 y 1907. Luego pasó a dirigir el departamento de biología de la Maine Agricultural Experimental Station (1907-1918), donde llevó a cabo importantes investigaciones sobre herencia y reproducción en aves y ganado. Posteriormente fue nombrado jefe de la división estadística del United States Food Administration (1917-1919), estudiando las relaciones entre alimentación y población. En 1918 comenzó su colaboración con la John Hopkins University, donde ocupó diversos puestos. Fue nombrado profesor de biometría y bioestadística en la Escuela de Higiene y Salud Pública, (1918-1925), profesor de biología en la Escuela de Medicina (1923-1940), profesor de investigación y director del Instituto de Investigaciones Biológicas (1925-1930) y estadístico del John Hopkins Hospital (1919-1935). Su reconocimiento internacional proviene, principalmente, de sus estudios estadísticos y pronósticos sobre la evolución de la población mundial en materia de demografía. Para más información, véase: JenNingS, H. J. (1942), «Raymond Pearl, 1879-1940», Biographical Memoirs of the National Academy of Sciences, 22, 295-331.

15 Pearl, R. \& A. M. Boring (1918), «Sex Studies X. The Corpus Luteum in the Ovari of the Domestic Fowl», Am. J. Antomy, 23(1): 1-35.

16 GoOdAle, H. D. \& J. F. NONÍDEZ (1924), «Luteal Cells and Hen-feathering», Amer. Nat., 58, 654, 91-92.

17 Crawford, R. D. (1990), Poultry Breeding and Genetics, Nueva York, Elsevier, p. 63. 
Durante muchos años Nonídez y Goodale siguieron colaborando juntos en distintos proyectos, así ambos llevaron a cabo una serie de investigaciones sobre la influencia de la dieta en la cría de gallinas en condiciones de producción masiva ${ }^{18}$. El estudio de los factores que intervienen en la producción de huevos y en el desarrollo óptimo de las aves de corral comenzó en los Estados Unidos alrededor de 1900, en buena parte centrado alrededor de la Maine Agricultural Experimental Station y, principalmente, en la figura del anteriormente mencionado Raymond Pearl. De este modo, se pasó de la cría y selección de razas de aves de corral principalmente por razones estéticas, a la cría de las mismas por motivos de productividad alimentaria, es decir, por su carne y huevos. La importancia de este cambio queda reflejada en el siguiente dato. En 1905 George K. Holmes del Bureau of Statistics de los Estados Unidos estimaba que el valor de pollos y huevos había ya igualado el valor de la producción nacional trigo, que se estimaba en medio billón de dólares al año ${ }^{19}$. En los años siguientes, muchas otras instituciones y centros incorporaron este tipo de estudios en sus líneas de investigación. Este fue el caso de la Mount Hope Farm, granja de investigación situada en Williamtown (Massachusetts) propiedad del hijo político de Rockefeller, donde el profesor Goodale ensayó la cría de pollos en condiciones distintas de iluminación y dieta para averiguar los factores que determinaban la aparición del raquitismo en las aves de corral, así como de otras disfunciones relacionadas con la alimentación y la cría de animales a gran escala, como era en las aves la debilidad de las patas. Las conclusiones de este trabajo indicaban que la adición de determinados complementos a la dieta, como el hígado de bacalao o la mantequilla, así como la iluminación con luz ultravioleta, factores que ayudan a la síntesis de la vitamina D o antiraquítica, podían reemplazar el efecto de la luz solar, de modo que era posible criar pollos en el interior de naves, desarrollándose éstos con normalidad. El estudio anatómico-histológico de las aves raquíticas y de aquéllas que mostraban una gran debilidad en las patas le fue encargado a Nonídez, quien observó una hiperplasia del paratiroides en ausencia de luz ultravioleta o su equivalente en vitamina antiraquítica ${ }^{20}$.

Como decíamos antes, el objetivo de los experimentos de cría en ausencia de luz solar y con distinta dieta respondía a la necesidad, cada día más apremiante, de criar animales a nivel industrial. De la eficacia con que las aves de corral convierten el alimento en su propio aumento de peso y en huevos depende finalmente los costes de producción. Otro punto importante que comenzó a estudiarse por la misma época, fue el modo de mantener unos buenos niveles de higiene en las granjas de producción

18 En la American Philosophical Society de Filadelfia se conserva la correspondencia que Goodale intercambió con Nonídez sobre este tema, Ms. B7GG1.

19 Cooke, K. J. (1997), «From Science to Practice, or Practice to Science? Chickens and Eggs in Raymond Pearl's Agricultural Breeding Research, 1907-1916», Isis, 88: 62-86.

20 NonídEZ, J. F. \& H. D. Goodale (1927), «Histological Studies on the Endocrines of Chickens Deprived of Ultraviolet Light», Am. J. Anatomy, 38, 319-347. 
masiva, para evitar la aparición de enfermedades como la coccidiosis, que provocaban enormes pérdidas ${ }^{21}$.

\section{Las células $\mathrm{C}$ y la Calcitonina}

Como complemento a sus estudios anteriores y para dar respuesta a la hiperplasia del paratiroides que presentaban los pollos raquíticos, con debilidad en las patas o con temblores, Nonídez comenzó a extirpar las glándulas paratiroideas a esos pollos, pero los resultados obtenidos no eran nunca tan marcados como los que se presentaban en mamíferos. En este caso, únicamente se apreciaba un estado pasajero de depresión que comenzaba a los 7 o 10 días de la operación que al cabo de una semana desaparecía y los pollos se recuperaban normalmente. Nonídez sospechaba que su recuperación se debía a la existencia de tejido paratiroideo en el timo, el cual probablemente experimentaba también una hipertrofia. Al término de su colaboración con Goodale, Nonídez extendió sus investigaciones sobre el tiroides a otros animales, estudiando la inervación de la glándula tiroides en el perro y en otros mamíferos, en donde aplicó el método de tinción con nitrato de plata de la escuela histológica de $\mathrm{Cajal}^{22}$. Con dicho método Nonídez observó la separación espontánea de ciertas células que ocupaban primeramente la pared de los folículos o vesículas del tiroides, y luego iban a situarse al lado de aquéllas en los espacios interfoliculares, razón por lo que las denominó «células parafoliculares».

Dichas células habían sido descritas por primera vez por E. Cresswall Baber en 1876 en el tiroides del perro, donde son particularmente numerosas y voluminosas. Años más tarde, en 1894, K. Hürthle confirmaba su presencia, si bien ambos autores mantenían una opinión contraria a la de Nonídez con respecto a su origen, suponiéndolas células epiteliales libres que se incorporaban gradualmente a los folículos y que por su citoplasma de apariencia granulosa fueron denominadas células parenquimatosas $^{23}$. De este modo, la poco acertada descripción de estas células por Hürthle llevó

21 MNCN, Nonídez a Cándido Bolívar, Woods Hole, 12 de septiembre de 1925. Cándido Bolívar: caja P18, correspondencia con J. F. Nonídez.

22 NoníDEZ, J. F. (1930), «Vascular Innervation of the Thyroid Gland», en Time, W., et al, The Vegetative Nervous Systems: An Investigation of the Most Recent Avances. The Proceedings of the Association for Research in Nervous and Mental Disease, New York, December $27^{\text {th }}$ and 28 $8^{\text {th }}$, 1928, Baltimore, Williams \& Wilkings, pp. 366-384; NONíDEZ, J. F. (1931a), «Innervation of the Thyroid Gland. I. The Presence of Ganglia in the Thyroid of the Dog», Arch. Neurol. Psych., 25(6), 1175- 1190 y Nonídez, J. F. (1931b), «Innervation of the Thyroid Gland. II. Origin and Course of the Thyroid Nerves in the Dog», Am. J. Anatomy, 48(2), 299-329.

23 BABER, E. C. (1876), «Contributions to the Minute Anatomy of the Thyroid Gland of the Dog», Proceedings R. Soc. London, 24, 240; y HÜRTHLE, K. (1894), «Beiträge zur kenntnis des sekretionsvorganges in der schilddrüse», Arch. Ges. Physiol., 56: 1-44. 
a la confusión a J. Ewing y a otros investigadores posteriores, quienes las asimilaron con unas células grandes y eosinófilas que aparecen en el tiroides humano como condición patológica, confusión que se prolongó durante años.

En siguiente paso significativo en la identificación de estas células, fue, como mencionabamos, la aplicación del método de impregnación argéntica efectuado por Nonídez ${ }^{24}$. Con dicho método Nonídez observó la presencia de un tipo celular argentófilo y de gran volumen, que correspondía a las células parafoliculares, del todo diferenciado de las células foliculares. Además, observó que el primer tipo de células no eran elementos de naturaleza embrionaria destinados al crecimiento en superficie de los folículos, sino células esencialmente diferentes que constituían un segundo tipo de epitelio ${ }^{25}$ y, por tanto, una fase en la diferenciación de los folículos. De este modo, propuso que el tiroides debía poseer una doble secreción, representada por el coloide que se acumulaba dentro de los folículos y la secreción de las células parafoliculares, vertida directamente a la corriente sanguínea y que estaba relacionada con el sistema endocrino difuso. Asimismo, Nonídez relacionaba esta secreción con las fases de crecimiento rápido características de los primeros meses de vida postnatal.

Sólo tras el avance de la microscopía electrónica, las técnicas histoquímicas y, posteriormente, las enzimocitoquímicas se pudo desvelar el verdadero origen y función de las células parafoliculares, actualmente conocidas como células C. Resumiendo, se reconoce ahora la existencia de dos tipos de células en el tiroides, aquellas productoras de la hormona tiroxina o células foliculares y las células $\mathrm{C}$, que a finales de la década de 1960 fueron identificadas como las productoras de la calcitonina $^{26}$, hormona que regula el equilibrio del calcio y, por tanto, como observaba Nonídez, especialmente importante durante los primeros años de vida, cuando los huesos crecen rápidamente. Concretamente, la calcitonina, producida también en otros órganos, inhibe la destrucción de los huesos e impide la elevación de los niveles de calcio en sangre. Igualmente facilita la absorción de calcio por el intestino, lo que puede llevar al incremento de los niveles de calcio en sangre, si bien, en este caso, de un modo indirecto estimulando la producción de vitamina $\mathrm{D}$ por los riñones. La ausencia de las condiciones necesarias para la producción de la vitamina $\mathrm{D}$, como ocurría con los pollos

24 NoníDEZ, J. F. (1932a), «Further Observations on the Parafollicular Cells of the Mammalian Thyroid», Anat. Rec., 53 (3), 339-353; NONÍDEZ, J. F. (1933a), «The «Parenchymatous» Cells of Baber, the 'Protoplasmareichen Zellen' of Huerthle, and the 'Parafollicular' Cells of the Mammalian Thyroid», Anat. Rec., 56(2), 131-142.

25 NONíDEZ, J. F. (1932b), «The Origin of the «Parafollicular» Cell, a Second Epithelial Component of the Thyroid of the Dog», Am. J. Anatomy, 49(3), 479-505. Como resumen de sus trabajos, se publicó en castellano: NONÍDEZ, J. F. (1933b), «Las células parafoliculares de la glándula tiroides», Investigación y Progreso, año VII, 4, 97-100.

26 Para más información sobre el descubrimiento de las células $\mathrm{C}$ del tiroides véase: Bussolati, G. (1997), «Le cellule C (parafollicolari) della tiroide: prospetto storico», Pathologica, 89(2): 15 pp. Versión online: http://www.siapec.it/pathologica/path_972_2.htm. 
criados por Goodale, produce una hiperplasia del paratiroides para intentar elevar la síntesis interna de esta vitamina. En casos prolongados se produce también la descalcificación de los huesos para compensar la falta de calcio en sangre, lo que puede ser una de las razones de la debilidad de las piernas en pollos observada por Nonídez.

\section{Regulación Refleja de la Presión Sanguínea. El glomus aorticum}

A partir de 1935, Nonídez cambió el rumbo de sus investigaciones, publicando ahora una serie de artículos sobre la base anatómica de la regulación refleja de la presión sanguínea. El descubrimiento de nervios sensitivos o aferentes para la regulación automática de la presión sanguínea databa de 1865, cuando Elie de Cyon y Ludwig hallaron en el conejo unos nervios que se extendía a cada lado del cuello hacia el corazón, los cuales, debido al retardo o depresión del ritmo cardiaco que producían tras su excitación eléctrica, fueron llamados nervios depresores. Sesenta años después de su descubrimiento, en 1924 Jorge Francisco Tello ${ }^{27}$ efectuó su estudio histológico aplicando el método del nitrato de plata de Cajal a embriones, con lo que demostró que el nervio depresor derecho terminaba en la base de la arteria subclavia de dicho lado, mientras que el izquierdo se distribuía sobre un segmento limitado del arco o cayado de la aorta en las proximidades del origen de la subclavia izquierda, como fue confirmado posteriormente en humanos por A. Tschernjachiws$\mathrm{ky}^{28}$. La segunda etapa en la investigación de la regulación refleja de la presión sanguínea fue inaugurada por los estudios fisiológicos de Corneille J. F. Heymans (1892-1968) y su escuela, quienes demostraron la existencia de reflejos cardiovasculares originados en el área de bifurcación de la arteria carótida común y, en concreto, en la porción dilatada o seno carotídeo que se encuentra radicado en la base de la carótida interna.

Desde finales del siglo XVIII se conocía la existencia de una curiosa estructura en la región del seno carotídeo llamada glomus caroticum o cuerpo carotídeo. La estructura e inervación del glomus fue descrita pormenorizadamente por el alumno de Cajal, Fernando de Castro (1896-1967), en 1926. Se trataba de un pequeño órgano epiteloidal localizado justo por encima y a ambos lados de la bifurcación de la arteria carótida, que estaba formado por un grupo principal de células granulares y otro secundario de carácter no granular sobre un lecho vascular sinusoidal y ricamente en-

27 Tello, J. F. (1924), «Développement et terminaison du nerf déppreseur», Trav. Labor. Rech. Biol. Univ. Madrid, 22, 295-309.

28 TSCHERNJACHIWSKY (1929), «Note sur le développement du système nerveux du coeur, la terminaison du nerf dèppresseur et l'innervation du sinus carotidium», Trav. Labor. Rech. Biol. Univ. Madrid, XXV, p. 75 y ss. 
tretejido por fibras sensoriales del nervio glosofaríngeo ${ }^{29}$. Dos años más tarde, de Castro $^{30}$ publicó un admirable trabajo que junto al anterior demostraba que, en contra de la idea del momento de que el glomus era un tipo de glándula endocrina similar a las glándulas suprarrenales, se trataba de un órgano cuya función era reaccionar a las variaciones de la composición de la sangre a través de quimioreceptores. Estas conclusiones fueron prácticamente simultáneas e idénticas a las alcanzadas por Hering ${ }^{31}$.

Durante un congreso celebrado en Burdeos en 1929, de Castro conoció a Heymans, quien aprovechó la ocasión para invitar al español a pasar unos días con él en Gante y poder discutir sus estudios acerca del seno carotídeo. Hasta ese momento Heymans había estado más interesado en estudiar los fenómenos vasopresores sobre la zona cardioaórtica, no habiendo iniciado aún el estudio fisiológico del cuerpo carotídeo. En 1931, Heymans y colaboradores emprendieron una investigación experimental para determinar si esos supuestos quimioreceptores eran los responsables de los reflejos respiratorios provocados por los cambios de composición de la sangre. A través de la destrucción localizada en el área del seno carotídeo fueron capaces de parar reflejos iniciados por cambios en la presión sanguínea, pero estos mismos reflejos aún persistían si habían sido iniciados en respuesta a cambios en la composición de la sangre. Parecía, sin embargo, que el mecanismo del nervio depresor intervenía únicamente en una pequeña parte de los reflejos respiratorios producidos por marcados descensos del nivel de oxígeno y que la vía de regulación esencial era en el glomus caroticum.

Investigaciones subsiguientes condujeron al descubrimiento e identificación de los quimioreceptores implicados en las zonas del seno carotídeo y cardioaórtico, así como a la definición de su modo de acción ${ }^{32}$. Por estos trabajos Heymans recibió en 1938 el premio Nobel de Fisiología y Medicina. No obstante, queremos expresamente hacer constar la contribución que los españoles de Castro y Nonídez efectuaron a esas investigaciones. El primero, de Castro, fue quien describió el glomus caroticum y mostró su importancia a Heymans. Desafortunadamente, el inicio de la guerra civil española le impidió finalizar sus experimentos sobre el significado y función de este órgano ${ }^{33}$. En

29 CASTRO, F. de (1926), «Sur la structure et l'innervation de la glande intercarotidienne (glomus caroticum) de l'homme et des mammifèros, etc.», Trav. Labor. Rech. Biol. Univ. Madrid, XXIV, p. 365 y ss.

30 CASTRO, F. de (1928), «Sur la structure et l'innervation du sinus carotidien du l'homme et des mammifères», Trav. Labor. Rech. Biol. Univ. Madrid, XXV, p. 331 y ss.

31 HENRING (1927), Die Karotissimusreflex auf Herz und Gefäse von normal -Physiologïschen, Pathologisch-Physiologischen und Klinischen Standpunkt, Dresden.

32 HeYmans, C. (1929), Le sinus carotidien et les autres zones vasosensibles reflexogenes: leur role en physiologie en pharmacologie et en pathologie, Louvain, Secretariat de la Revue; HEYMANS, C.; BOUCKAERT, J. J.; REGNIERS, P. (1933), Le sinus carotidien et la zone homologue cardio-aortique; physiologie, pharmacologie, pathologie, clinique, París, G. Doin \& Cie.

33 El mismo De Castro comentaba: «Naturalmente que la pérdida de tiempo que hubo desde mil novecientos treinta y seis a mil novecientos treinta y ocho por motivo de nuestra guerra fue tremendo, porque yo estaba haciendo entonces experiencias de las anastomosis nerviosas. Era el poder registrar automáticamente el fenómeno de los reflejos carotídeos sobre el ojo, con las anastomosis nerviosas, 
su momento Heymans reconoció, durante un viaje a Argentina donde coincidió con de Castro, que el premio Nobel debía haber sido compartido con el español.

Del mismo modo, poco antes de la guerra, entre 1934 y 1935 G. Muratori ${ }^{34}$ y Nonídez descubrieron, independientemente, dos órganos de estructura idéntica al glomus caroticum, situados en el conejo y en el gato por encima del arco o cayado de la aorta, que el español denominó glomi aortici o cuerpos aórticos ${ }^{35}$. A diferencia de Muratori, quien los consideraba formaciones paraganglionares, Nonídez insistió sobre la naturaleza sensitiva de sus terminaciones nerviosas, que fue confirmada más tarde por Hollinshead, así como sobre su función quimioreceptora, también comprobada experimentalmente por Comroe y Verdonk en 193936. Las fibras nerviosas que terminaban en los cuerpos aórticos se desprendían del nervio depresor. En el perro y el hombre la posición de estos órganos era diferente, por no estar situados encima sino debajo del arco de la aorta, junto al paragánglio de Penitschka ${ }^{37}$. La inervación de este último era idéntica a la de los cuerpos aórticos, concluyendo que se trataba también de un quimioreceptor, cuya posición presentaba, como decíamos, diversas modificaciones anatómicas dependiendo del animal de estudio ${ }^{38}$. Como en el caso anterior, los cuerpos aórticos presentan quimioreceptores que responden fundamentalmente al descenso de la tensión de oxígeno en la sangre, siendo algo menos sensibles a los descensos de $\mathrm{pH}$ sanguíneo o a los incrementos de dióxido de carbono ${ }^{39}$.

Posteriormente, Nonídez continuó sus estudios histológicos, pero esta vez dirigidos a averiguar las estructuras implicadas en la regulación de la presión sanguínea a través de presoreceptores. En 1915 Brainbridge describió un reflejo, producido cuando se

mediante la variación química de la sangre. Luego lo lleve a un simposio a Estocolmo, en que la primera conferencia estaba a cargo de Heymans, y la segunda, a cargo mío. Allí expliqué mis trabajos, que no puede terminar durante la guerra, porque me quedé sin los gatos, puesto que en aquel tiempo difícil se me murieron de hambre o tuve que matarlos. Por esa razón yo no pude finalizar mis experimentos en aquel momento»; GómeZ-SAnTos, M. (1968), Cinco grandes de la ciencia española, Madrid, Biblioteca Nueva, pp. 123-125, cita en p. 124.

34 MURATORI, G. (1934), «Contributo istologico all innervazione della zona arteriosa glomocariotidea», Arch. Ital. Anat. Embr., 33, 421 y ss.; y MURATORI, G. (1935), «Connessioni tra tessuto paraganglio e zone recettrici aortiche in vari mammiferi», Monit. Zool. Ital., 45, 300-310.

35 NonídeZ, J. F. (1935b), «The Presence of Depressor Nerves in the Aorta and Carotid of Birds», Anat. Record, 62(1), pp. 47-66; Nonídez, J. F. (1935c), «The Aortic (Depressor) Nerve and its Associated Epithelioid Body, the Glomus Aorticum», Am. J. Anatomy, 57 (2), 259-301.

36 NoníDEZ, J. F. (1940a), «La base anatómica de la regulación refleja de la presión sanguínea», Ciencia, 1(2), 49-56.

37 NoníDEZ, J. F. (1937a), «Distribution of the Aortic Nerve Fibers and the Epithelioid Bodies (Supracardial «Paraganglia») in the Dog», Anat. Rec., 69 (3), 299-317.

38 NonídeZ, J. F. (1936a), «Observations on the Blood Supply and the Innervation of the Aortic Paraganglions of the Cat», J. Anatomy, 70(2): 215-228.

39 Para más información sobre los reflejos respiratorios y los quimioreceptores implicados en los mismos, véase: Sukhamay Lahiri (ed.) (1989), Chemoreceptors and Reflexes in Breathing: Cellular and Molecular Aspects. The Julius H. Comroe Memorial Volume, Nueva York, Oxford University Press. 
aumentaba la presión sanguínea en la vena cava superior mediante inyección de suero fisiológico, de sentido contrario al de Cyon-Ludwing, es decir, que provocaba una aceleración del ritmo cardiaco o taquicardia, con aumento de presión arterial. El estudio de dicho reflejo indicaba que las zonas en donde radicaban las terminaciones presoreceptoras, arborizaciones extensas de la fibra nerviosa que responden a los cambios de presión, se hallaban próximas al corazón y que algunas debían también encontrarse en las aurículas. Nonídez demostró la presencia de dichos presoreceptores no sólo en la vena cava superior, sino también en la inferior, el seno coronario y las venas pulmonares ${ }^{40}$.

Derivado de los estudios anteriores, entre 1936 y 1937 publicó una serie de tres artículos dando a conocer los resultados de sus investigaciones sobre la naturaleza histológica del «retículo terminal»de las fibras nerviosas, basándose en observaciones procedentes de sus estudios anteriores sobre los vasos sanguíneos y el tiroides, completadas con datos de los ganglios y nervios del sistema autónomo. Dichas investigaciones estaban en relación con una enconada polémica en torno al modo de terminación de las fibras autónomas del sistema nervioso vegetativo, iniciada en 1935. La postura clásica, mantenida por investigadores como Lawrentjew, Fedorow y Matwejewa y de Castro, era que las fibras autónomas poseían terminaciones libres, mientras la nueva teoría mantenía que las fibras finalizaban en un retículo terminal formado por una masa sincitial de neuroplasma que constituía una delicada malla neurofibrilar; posición seguida por Reiser, Stöhr, Harting y Szantroch. Mientras los primeros acusaban a los segundos de que sus resultados se debían a un artificio, Nonídez, en una serie de experimentos en los que empleó las técnicas de tinción de carbonato de plata de Río Hortega y las de nitrato de plata reducido de Cajal, demostró que si bien los datos del segundo grupo no podían negarse, la estructura observada carecía de naturaleza nerviosa. El error se hallaba en el método de tinción empleado. El método Beilschowsky original, que modificado había sido utilizado extensivamente para el sistema nervioso con resultados poco reproducibles, en realidad había sido ideado para teñir finas fibras de tejido conectivo en distintos órganos. Por ello, Nonídez supuso que al aplicarlo al estudio de las fibras nerviosas se estaban tiñendo tanto éstas como las porciones más finas del tejido conectivo estructural de los órganos que las sostenían, lo que él mismo, decía, había observado en ciertas ocasiones. Los métodos de la escuela histológica española aplicados confirmaron por doble partida la naturaleza conectiva del retículo, rechazando su posible carácter nervioso ${ }^{41}$.

40 NoníDEZ, J. F. (1937b), «Identification of the Receptor Areas in the Venal, Caval and Pulmonary Veins which Iniciate Reflex Cardiac Acceleration (Bainbridge's reflex)», Am. J. Anatomy, 61(2), 203-231.

41 Nonídez, J. F. (1936b), «The Nervous Terminal Reticulum. A Critique. I. Observations on the Innervation of the Blood Vessels», Anatomischer Anzeiger, 82, 348-366; NoNíDEZ, J. F. (1937c), «The Nervous Terminal Reticulum II. Observations on Thyroid and the Liver», Anatomischer Anzeiger, 84, 1 13; y NoníDEZ, J. F. (1937d), «The Nervous Terminal Reticulum. A Critique. III. Observations on the 
Estos métodos de tinción también fueron utilizados por Nonídez para el estudio histológico de la naturaleza de las fibras nerviosas del corazón, de modo que se pudieran distinguir las fibras postganglionares del sistema simpático de las del parasimpático. La observación de una tinción más débil en los axones de las células postganglionares del simpático ${ }^{42}$, contribuyó a discernir la distribución de ambos sistemas en el corazón, punto de importancia dado que estos ejercen influencias contrarias sobre el mismo.

Para completar la exposición de lo que fueron las líneas principales de investigación de Nonídez, hay que mencionar, además, la publicación de dos manuales de su disciplina en los Estados Unidos. Estos fueron Histology and Embriology, que se editó en 1941 y, con carácter póstumo, Texbook of Histology, libro escrito junto a W.F. Windle que llegó a alcanzar cinco ediciones más ${ }^{43}$ tras su muerte en 1947.

Como puede observarse, Nonídez colaboró, si bien no en con un papel estelar, en algunas de las cuestiones más candentes de la investigación biológica de la primera mitad del siglo XX. Aunque su carrera investigadora transcurrió en los Estados Unidos, no despreció los avances técnicos desarrollados en su país de origen si no que colaboró en su difusión demostrando su importancia. Así y principalmente al final de su vida, Nonídez volvió a acercarse a España, al menos en lo que respecta a la tradición y líneas de investigación de algunos de sus compatriotas de la escuela histológica de Cajal, como por la utilización de los métodos de tinción de esta escuela, considerados por Nonídez como «una técnica neurohistológica irreprochable».

Autonomic Ganglia and Nerves with Special Reference to the Problem of the Neuro-neuronal Synapse. Concluding Remarks», Anatomischer Anzeiger, 84, 315-330.

42 NoníDEZ, J. F. (1939), «Studies on the Innervation of the Heart. I. Distribution of the Cardiac Nerves, with Special Reference to the Identification of the Sympathetic and Parasynpathetic Postganglionics, Am. J. Antomy, 65 (3), 363-413; NONíDEZ, J. F. (1940b), «Diferencias en la argentofilia de las fibras nerviosas; su importancia en el estudio del corazón», Ciencia, 1 (5), 203-205; y Nonídez, J. F. \& K. Hare (1940), «Differences in the Argyrophilia of Sympathetic Postganglionics and of other Nerve Fibers», Anat. Rec., 76(2), Suppl., p. 44.

43 NoníDEZ, J. F. (1941), Histology and Embriology, Londres, Nueva York, Oxford University Press; y NonídeZ, J. F. \& WindLE, W. F. (1949), Textbook of Histology, New York, Mc Graw-Hill Book Co. Esta última obra alcanzó cinco ediciones: 1949, 1953, 1960, 1969 y 1976. 